\title{
Use of Age-Albumin Ratio as a Single Predictor of 30-Day Mortality after Colectomy
}

\author{
Chih-Chien Chin ${ }^{\mathrm{a}, \mathrm{b}}$ Ching-Ho Yen ${ }^{\mathrm{c}}$ Wen-Li Hsu ${ }^{\mathrm{d}}$ Jeng-Yi Wanga,b Chia-Hao Chang ${ }^{\mathrm{e}, \mathrm{f}}$ \\ a Section of Colon and Rectal Surgery, Department of Surgery, Chang Gung Memorial Hospital, Chiayi, \\ ${ }^{b}$ Graduate Institute of Clinical Medical Science, College of Medicine, Chang Gung University, Taoyuan, \\ ${ }^{c}$ Department of Industrial Engineering and Management Information, Huafan University, Taipei, \\ ${ }^{\mathrm{d}}$ Division of Hematology and Oncology, Department of Medicine, Chang Gung Memorial Hospital, \\ ${ }^{\text {e }}$ Department of Nursing, \\ ${ }^{f}$ Chronic Diseases and Health Promotion Research Center, Chang Gung University of Science and Technology, Chiayi, Taiwan
}

\section{Keywords}

Colorectal cancer · Postoperative mortality

Age-albumin ratio $\cdot$ Receiver operating characteristic curve

\section{Summary}

Background: Colorectal cancer is among the three leading cancers and causes of mortality worldwide. It is important to develop an effective single-parameter screening technique for reducing the postoperative mortality rate. Previous studies have proved that patient age is a major factor influencing postoperative mortality. A strong association has been reported between serum albumin and patient age. We aimed to identify new predictors on the basis of age-albumin ratio (AAR) for assessing 30-day mortality after colectomy. Patients and Methods: Detailed information about patients with colon cancer was retrieved from the Colorectal Section Tumor Registry at Chang Gung Memorial Hospital, Taiwan. The study subjects comprised 3,732 consecutive patients with colon cancer who had undergone elective, potentially curative surgery. Results: The area under the receiver operating characteristic curve (AUC) of the AAR was significantly larger than the AUC of serum albumin. The low specificity of AAR was compensated by its substantially high sensitivity. An AAR of $\geq 20$ years $\mathrm{g}^{-1} \mathrm{nl}^{-1}$ was found to be the most prevalent threshold value. Conclusion: The present investigation suggests that AAR can be used in clinical practice as a simple parameter for the identification of patients at risk of 30-day mortality after colectomy.
Schlüsselwörter

Kolorektales Karzinom · Postoperative Mortalität .

Alters-Albumin-Ratio - "Receiver Operating Characteristic»Kurve

\section{Zusammenfassung}

Hintergrund: Das kolorektale Karzinom gehört zu den drei führenden Krebserkrankungen und Todesursachen weltweit. Die Entwicklung einer effektiven Ein-Parameter-Screening-Technik zur Reduktion der postoperativen Mortalitätsrate ist bedeutend. Frühere Studien haben belegt, dass das Patientenalter ein wichtiger Faktor für die postoperative Mortalität ist. Ein ausgeprägter Zusammenhang von Serumalbumin und Patientenalter ist festgestellt worden. Wir beabsichtigten daher, auf der Grundlage der AltersAlbumin-Ratio neue Prädiktoren zur Beurteilung der 30Tage-Mortalität nach Kolektomie zu identifizieren. Patienten und Methoden: Detaillierte Informationen zu Patienten mit Dickdarmkrebs wurden aus der Colorectal Section Tumor Registry am Chang Gung Memorial Hospital, Taiwan, abgerufen. Die Probandengruppe setzte sich aus 3732 konsekutiven Patienten mit Dickdarmkrebs zusammen, die sich einer elektiven, potenziell kurativen Operation unterzogen hatten. Ergebnisse: Die Fläche unter der "Receiver Operating Characteristic»(ROC)-Kurve der Alters-Albumin-Ratio war signifikant größer als die ROC-Kurve des Serumalbumins. Die geringe Spezifität der Alters-Albumin-Ratio wurde durch deren erheblich höhere Sensitivität ausgeglichen. Eine Alters-Albumin-Ratio $\geq 20$ Jahre $\mathrm{g}^{-1} \mathrm{nl}^{-1}$ wurde als der am weitesten verbreitete Schwellenwert identifiziert. Schlussfolgerung: Die vorliegende Untersuchung deutet darauf hin, dass die Alters-Albumin-Ratio in der klinischen Praxis als einfacher Parameter zur Identifizierung von Patienten mit dem Risiko einer 30-Tage-Mortalität nach Kolektomie verwendet werden kann.

\section{KARGER \\ Fax +497614520714}

Information@Karger.com

www.karger.com
(C) 2013 S. Karger GmbH, Freiburg

$1662-6664 / 13 / 0292-0125 \$ 38.00 / 0$

Accessible online at:

www.karger.com/vim
Chia-Hao Chang, Ph.D.

Department of Nursing and Chronic Diseases and Health Promotion Research Center Chang Gung University of Science and Technology

2, Chia-pu Rd, West Sec. Pu-tz, Chiayi, 613, Taiwan

howellchang@gmail.com 


\section{Background}

Colorectal cancer is among the three leading cancers and causes of mortality worldwide, with about 1 million new cases and 528,978 deaths reported in 2002 [1-6]. The statistics and publications of the Department of Health of Taiwan indicate that colorectal cancer is the most commonly diagnosed cancer and the third leading cause of cancer-related deaths among both men and women in Taiwan [7]. It is therefore important to plan health care and to identify the risk factors for postoperative mortality in patients with colorectal cancer.

Despite improvements in surgical techniques, a mortality rate of 5-6.5\% has been reported for elective colorectal surgery with resection [8-11]. There is strong evidence that malnutrition increases adverse surgical outcome after major elective surgery [12]. Studies have indicated several malnutritionrelated risk factors for postoperative mortality [13, 14]. It is well established that hypoalbuminemia (serum albumin level $\leq 3.5 \mathrm{~g} / \mathrm{dl}$ ), as a marker of malnutrition, is strongly related to a high risk of adverse surgical outcomes [15-18]. Compared with other preoperative parameters, the serum albumin level is a frequently used predictor of malnutrition as well as risk of poor postoperative outcomes in clinical practice. One of the main advantages is the relatively low cost of the serum albumin test [19].

As noted in previous studies, the age of patients with colorectal cancer is another major predictor of adverse surgical outcomes. For example, in a previous study, the patients were divided into age groups of 0-59 years, 60-69 years, 70-79 years, 80 years, and $>80$ years, and the operative risk significantly increased in the older-age group [20]. Other studies, in which the patients were also divided into several age groups, used odds ratios of postoperative mortality for the different strata of patients. An increasing risk of postoperative mortality is observed with increasing age [21, 22]. Many recent studies can be referred to regarding the association of mortality and age [23-26]. All these studies aimed to discover that an increase in postoperative mortality rates is associated with aging. Overall, preoperative serum albumin level and age can prominently affect the postoperative outcomes of patients with colorectal cancer undergoing surgical treatment [27].

Many studies support the assumption that serum albumin levels decrease with age $[28,29]$. The ratio of age to serum albumin can be considered as a single and easy-to-determine index for predicting 30-day mortality; the significance of age can be weighed by dividing it by serum albumin. Use of receiver operating characteristic (ROC) curves is suggested for evaluating the diagnostic value of indices on the basis of a single cut-off value of a continuous variable [30]. Thus, it would be interesting to evaluate whether the application of a new index, based on the ratio of age and serum albumin, will increase the area under the ROC curves (AUC) for assessing 30-day mortality, compared with that of the index based on serum albumin alone. We expected this new index to be more
Table 1. Pathological and clinical characteristics of patients and 30-day mortality

\begin{tabular}{|c|c|}
\hline Parameter & Median (IQR) \\
\hline Age, years & $65(54-74)$ \\
\hline Height, $\mathrm{cm}$ & $159(153-165)$ \\
\hline Weight, kg & $59(52-67)$ \\
\hline Preoperative CEA level, ng/ml & $3.3(1.9-7.8)$ \\
\hline Serum albumin level, g/nl & $4.0(3.6-4.3)$ \\
\hline \multirow[t]{2}{*}{ Hemoglobin level, g\% } & $11.7(9.8-13.3)$ \\
\hline & $\mathrm{n}=3,732(\%)$ \\
\hline \multicolumn{2}{|l|}{ Medical illness - asthma } \\
\hline Yes & $119(3.19)$ \\
\hline No & $3,613(96.81)$ \\
\hline \multicolumn{2}{|l|}{ Medical illness - diabetes } \\
\hline Yes & $506(13.56)$ \\
\hline No & $3,226(86.44)$ \\
\hline \multicolumn{2}{|l|}{ Medical illness - liver cirrhosis } \\
\hline Yes & $48(1.29)$ \\
\hline No & $3,684(98.71)$ \\
\hline \multicolumn{2}{|l|}{ Tumor location } \\
\hline Right colon & $1,449(38.83)$ \\
\hline Left colon & $2,283(61.17)$ \\
\hline \multicolumn{2}{|l|}{ TNM stage } \\
\hline I & $488(13.08)$ \\
\hline II & $1,731(46.38)$ \\
\hline III & $1,513(40.54)$ \\
\hline \multicolumn{2}{|l|}{ 30-day mortality } \\
\hline Yes & $40(1.07)$ \\
\hline No & $3,692(98.93)$ \\
\hline
\end{tabular}

$\mathrm{IQR}=$ Interquartile range; $\mathrm{CEA}=$ carcinoembryonic antigen;

$\mathrm{TNM}=$ tumor node metastasis.

significantly related to 30 -day mortality than serum albumin alone. Finally, we attempted to determine the optimal cut-off value of the new index for predicting the risk of 30-day mortality after colectomy.

\section{Methods}

\section{Patients}

Detailed information about patients with colon cancer, such as patient- and tumor-related factors and follow-up status, was retrieved from the Colorectal Section Tumor Registry (CRSTR) at Chang Gung Memorial Hospital, Taiwan. All the data in this registry were prospectively collected. Patient demographic data, comorbidities, tumor characteristics, and postoperative mortality were included in the data collection. Patientrelated factors comprised age, height, weight, hemoglobin level, serum albumin level, carcinoembryonic antigen (CEA) level, and comorbidities. The following comorbidities that may influence the postoperative outcome were recorded in this study: asthma, diabetes, and liver cirrhosis. Tumor-related factors comprised location and stage. Tumors were staged according to the sixth edition of the American Joint Committee on Cancer (AJCC) tumor node metastasis (TNM) staging system. With regard to location, the tumors were categorized as those present in the right colon (from the cecum to the transverse colon) and as those present in the left colon (from the splenic flexure to the sigmoid colon). 
The study subjects comprised 3,732 consecutive patients with colon cancer who had undergone elective, potentially curative surgery at the Chang Gung Memorial Hospital from January 1995 to December 2008. Patients with metastatic disease (stage IV colon cancer) were excluded from the study since the treatments for these patients vary and are always palliative. Every patient in this study underwent standard oncological resection of the colon and received routine postoperative care.

\section{Statistical Analyses}

The pathological and clinical characteristics of the patients are shown in table 1 . To exclude the confounding factors, a logistic regression analysis was performed using a multivariate stepwise selection procedure to analyze the factors that significantly differed between patients with 30 day mortality and non-30-day mortality in the univariate analysis (inclusion factors were those with a $\mathrm{p}$ value of $<0.05$ determined by univariate analysis). The univariate analysis included the Wilcoxon test for medians and chi-square test or Fisher's exact test (if one of the cell counts was small or zero) for discrete data. Moreover, we have discussed the way of feature extraction from the significant factors derived from the logistic regression model (the ratio of the first and second significant factors). In order to determine the way having the strongest association with 30-day mortality, we derived the AUCs for the prediction of 30-day mortality by using each of the candidate predictors. Furthermore, we graphically compared the AUCs and tested the equality of the ROC curves by area test [31]. The main aim was to identify the best predictor of 30-day mortality in terms of sensitivity and specificity. The optimal threshold value (cut-off value) of each candidate predictor was calculated as follows:

Optimal cut-off value $=\min \left(\sqrt{(1-\text { sensitivity })^{2}+(1-\text { specificity })^{2}}\right)$

Table 2. Surgeryrelated complications in 40 patients with 30-day mortality

\begin{tabular}{lc}
\hline Complications & Incidence \\
\hline Lung (atelectasis, pneumonia) & 15 \\
CV (MI, CVA, embolism) & 5 \\
Bladder dysfunction & 1 \\
GI (obstruction, bleeding) & 4 \\
Anastomosis (leakage, stenosis) & 5 \\
Others & 6 \\
Combination & 4 \\
\hline
\end{tabular}

$\mathrm{CV}=$ Cardiovascular; $\mathrm{MI}=$ myocardial infarction; CVA = cerebrovascular accident; $\mathrm{GI}=$ gastrointestinal.
We determined the sensitivity and specificity for the prediction of 30day mortality on the basis of the threshold values of the candidate predictors. All the statistical analyses were conducted using the 'MASS' and 'ucR' packages of R 2.9.2 statistical software (R Foundation for Statistical Computing, Vienna, Austria) and Statistical Analysis System (SAS) 9.1.3 software (SAS Institute, Cary, NC, USA).

\section{Results}

\section{Demographic Data}

The pathological and clinical characteristics of the patients are shown in table 1 . The number of patients with 30-day mortality was 40 . The morbidity rate was $10.7 \%$ in the non-30-day mortality group and $100 \%$ in the 30 -day mortality group. Surgery-related complications in 40 patients with 30-day mortality are shown in table 2.

\section{Univariate and Multivariate Analyses of 30-Day Mortality}

By performing univariate analysis, we found that weight, age, preoperative CEA level, hemoglobin level, serum albumin level, asthma, diabetes, and liver cirrhosis were statistically significant (table 3). With regard to multivariate analysis, age, serum albumin level, and diabetes were found to be the significant predictors. Moreover, the logistic regression model from SAS revealed that patients whose age increased by 10 years, with the other factors remaining constant, were at a 1.852 times higher risk of mortality than the others. Patients whose serum albumin levels increased by one unit $(0.1 \mathrm{~g} / \mathrm{dl})$, with the other factors remaining constant, were $0.248(0.146-0.423)$ times more susceptible to mortality than the others. Similarly, patients with diabetes were 2.668 (1.286-5.542) times more susceptible to mortality than those without diabetes (table 3 ).

\section{AUCs of Serum Albumin and AAR for the Prediction of 30-Day Mortality}

The ratio of the first and second significant factors was agealbumin ratio (AAR) [32]. In order to assess which predictor
Table 3. Comparison of the pathological and clinical characteristics of patients with non-30-day and 30-day mortality

\begin{tabular}{|c|c|c|c|c|c|}
\hline & \multicolumn{2}{|c|}{ Univariate analysis } & \multicolumn{3}{|c|}{ Multivariate analysis } \\
\hline & Z/odds ratio & $\mathrm{p}$ value & odds ratio & $95 \% \mathrm{CI}$ & $\mathrm{p}$ value \\
\hline Height & -1.70 & 0.089 & - & - & - \\
\hline Weight & -4.09 & $<0.001$ & 1.000 & $(0.998-1.003)$ & 0.780 \\
\hline Age & 5.66 & $<0.001$ & 1.064 & $(1.026-1.103)$ & 0.001 \\
\hline Preoperative CEA level & 4.84 & $<0.001$ & 1.000 & $(0.996-1.004)$ & 0.947 \\
\hline Hemoglobin level & -2.58 & 0.010 & 1.008 & $(0.928-1.095)$ & 0.853 \\
\hline Serum albumin level & -6.10 & $<0.001$ & 0.248 & $(0.146-0.423)$ & $<0.001$ \\
\hline Medical illness - asthma & 3.46 & 0.037 & 2.947 & $(0.935-9.285)$ & 0.065 \\
\hline Medical illness - diabetes & 3.12 & 0.002 & 2.668 & $(1.286-5.542)$ & 0.008 \\
\hline Medical illness - liver cirrhosis & 9.21 & 0.002 & 3.244 & $(0.769-13.679)$ & 0.109 \\
\hline Tumor location & 0.77 & 0.420 & - & - & - \\
\hline TNM stage & 2.35 & 0.310 & - & - & - \\
\hline
\end{tabular}

$\mathrm{CI}=$ Confidence interval $\mathrm{CEA}=$ carcinoembryonic antigen $; \mathrm{TNM}=$ tumor node metastasis. 


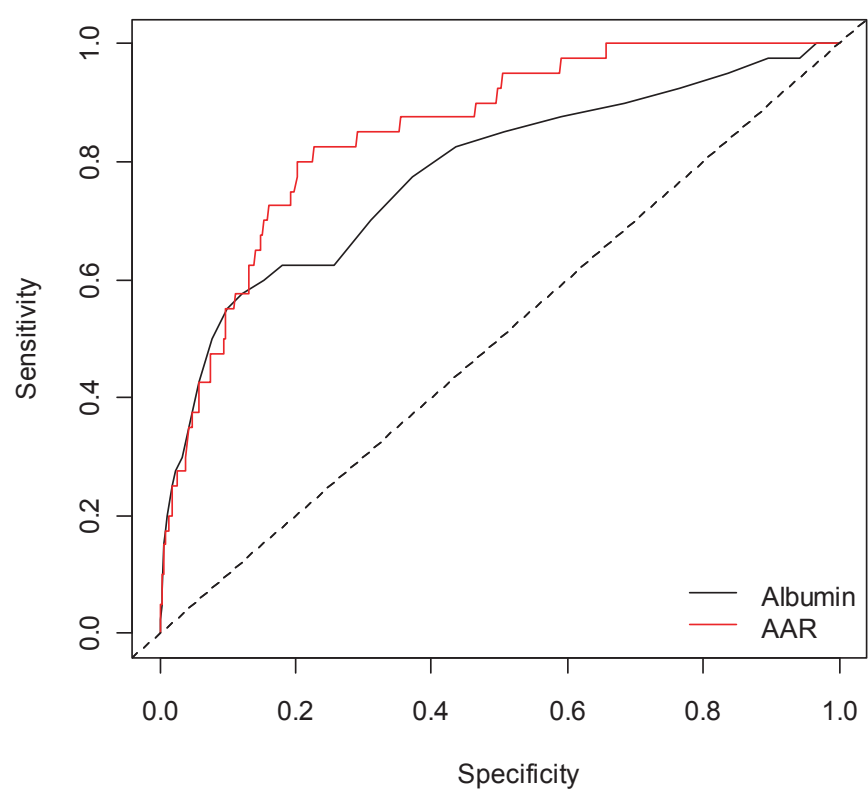

Fig. 1. ROC curves for serum albumin and AAR for the prediction of 30-day mortality.

(serum albumin or AAR) was more significantly related to 30-day mortality, we conducted the area test (results shown in table 4). Testing of the difference between serum albumin and AAR showed that the ROC curves for serum albumin and AAR were unequal. AAR had larger AUCs, while serum albumin had a significantly smaller AUC. Figure 1 shows the ROC curves for serum albumin and AAR for the prediction of 30-day mortality. We found that the ROC curve for AAR was almost consistently higher than that for serum albumin.

The values of sensitivity and specificity for the prediction of 30-day mortality, determined on the basis of the threshold values of serum albumin and AAR, are shown in table 5. The sensitivities are as follows: serum albumin level of $\leq 3.5$ $\mathrm{g} / \mathrm{nl}$ and $\mathrm{AAR}$ of $\geq 20$ years $\mathrm{g}^{-1} \mathrm{nl}^{-1}$. The specificities are as follows: serum albumin level of $\leq 3.5 \mathrm{~g} / \mathrm{nl}$ and AAR of $\geq 20$ years $\mathrm{g}^{-1} \mathrm{nl}^{-1}$.

\section{Discussion}

Our study has several strengths. To begin with, it is the first study that combined age with serum albumin, forming a new index to evaluate the postoperative 30-day mortality in patients with colon cancer. Additionally, by using AUCs, we were able to examine each (or any) combination of the risk factors to determine the one that was most strongly associated with adverse operative outcomes.

Bad food intake habits contribute to hypoalbuminemia [33]. Food intake was measured by a food frequency questionnaire in our study. Frequency of consumption in the recent 5 years was recorded for the following 12 food items: rice, bread, instant noodles, fish/shrimp, red meat, white meat, vis-
Table 4. AUCs for the prediction of 30-day mortality, derived on the basis of the threshold values of serum albumin and the new indices

\begin{tabular}{|c|c|c|}
\hline & AUC & $\mathrm{p}$ value \\
\hline Age-albumin ratio & 0.851 & - \\
\hline Serum albumin & 0.779 & 0.0002 \\
\hline
\end{tabular}

Table 5. Sensitivity and specificity for the prediction of 30-day mortality, determined on the basis of the threshold values of serum albumin and the new indices

\begin{tabular}{lll}
\hline & Sensitivity & Specificity \\
\hline Serum albumin level of $\leq 3.5 \mathrm{~g} / \mathrm{nl}$ & 0.625 & 0.81907 \\
Age-albumin ratio of $\geq 20$ years g ${ }^{-1} \mathrm{nl}^{-1}$ & 0.800 & 0.79605 \\
\hline
\end{tabular}

cera, eggs, vegetables, milk, coffee, and fruit. However, we found that all of the 12 items were not statistically significant in regard to mortality. Traditionally, hypoalbuminemia is associated with a high risk of adverse surgical outcomes [15-18]. Serum albumin is a better prognostic predictor of operative outcome than anthropomorphic markers of nutritional status. Older patients often have many coexisting diseases and develop hypoalbuminemia; i.e., serum albumin levels decrease with age, and this association is independent of sex. On the basis of these findings, many studies have suggested preoperative low serum albumin levels and old age as the fundamental factors that increase 30-day mortality after colorectal surgery $[8,24,25]$. In clinical practice, the most important advantage is that the serum albumin test is a relatively low-cost test, and age determination is easy. The AAR is an index that assessed older patients by the stricter criteria. Our results show that the percentage of the AAR of $\geq 0.8$ years $\mathrm{g}^{-1} \mathrm{nl}^{-1}$ in cases of mortality has higher values $(80 \%)$. Hence, a combination of the two parameters of age and serum albumin should be used more frequently as a prognostic tool to predict postoperative mortality. Concomitant medical illnesses such as asthma, diabetes, and liver cirrhosis have also been reported in several studies as significant predictors of 30-day mortality [13, 34, 35]. The results of this study are in accordance with those of the studies cited above. Specific postoperative complications were identical in the 30-day mortality group and the non-30day mortality group. However, there were more pulmonary complications in the 30-day mortality group than in the non30 -day mortality group ( 37.5 vs. $0.4 \% ; \mathrm{p}<0.001)$. This implies that postoperative pulmonary complications are frequent in terms of 30-day mortality. Moreover, serum albumin level and the patient's age were parameters having a high correlation with pulmonary complications $[23,36]$. In our study, means of AAR were compared in both groups. The values were significantly different between those with and without pulmonary complication $(16.54 \pm 5.16$ vs. $26.65 \pm 7.81 ; p<0.001)$. In multivariate analysis, among the patient-related factors and co- 
Table 6. Percentage of the considered measurements in cases of morbidity and mortality

\begin{tabular}{lllllll}
\hline \multicolumn{7}{c}{ Percentage, $\%$} \\
\cline { 2 - 7 } & lung & $\mathrm{CV}$ & $\begin{array}{l}\text { bladder } \\
\text { dysfunction }\end{array}$ & GI & anastomosis & mortality \\
\hline Albumin of $\leq 3.5 \mathrm{~g} / \mathrm{nl}^{-1} \mathrm{ll}^{-1}$ & 75.9 & 42.9 & 45.8 & 18.2 & 31.3 & 62.5 \\
AAR of $\geq 20$ years g & 86.2 & 42.9 & 50.8 & 23.6 & 29.2 & 80.0 \\
\hline
\end{tabular}

$\mathrm{AAR}=$ Age-albumin ratio $\mathrm{CV}=$ cardiovascular $; \mathrm{GI}=$ gastrointestinal .

morbidities, preoperative serum albumin level, age, and diabetes were observed to be markedly associated with the postoperative 30-day mortality in patients with colon cancer. Furthermore, patients whose serum albumin levels increased by one unit $(0.1 \mathrm{~g} / \mathrm{dl})$, with the other factors remaining constant, were 0.248 times more susceptible to mortality than the others. The risk of 30-day mortality was 1.852 times higher in patients whose age increased by 10 years than in others. Similarly, patients with diabetes were 2.668 times more susceptible to mortality than those without diabetes.

The present study mainly showed that combining two continuous predictors (preoperative serum albumin level and age) significantly affected the prediction of postoperative mortality in patients with colon cancer. In this study, we proposed the use of AAR as a screening parameter for identifying the optimal cut-off value in order to predict the 30-day mortality after colon surgery. AAR of $\geq 20$ years $\mathrm{g}^{-1} \mathrm{nl}^{-1}$ yielded the minimal value of

$\sqrt{(1-\text { sensitivity })^{2}+(1-\text { specificity })^{2}}$

for predicting 30-day mortality. The low specificity was compensated by its substantially high sensitivity. In other words, the new index would offer built-in solutions for situations in which individuals with high risks of 30-day mortality are falsely assumed to have no risk. Moreover, the optimal cut-off values recommended in this study for AAR showed a balance of sensitivity and specificity for the prediction of 30-day mortality (table 5).

Table 6 shows the percentage of the considered measurements in cases of morbidity and mortality. For 30-day mortality, AAR of $\geq 0.8$ years $\mathrm{g}^{-1} \mathrm{nl}^{-1}$ has higher values $(80 \%)$ than serum albumin of $\leq 3.5 \mathrm{~g} / \mathrm{nl}(62.5 \%)$, mGPS (modified Glasgow prognostic score) of $\geq 1(52.5 \%)$, and mGPS of $\geq 2$ $(32.5 \%)$. For pulmonary complications, AAR of $\geq 0.8$ years $\mathrm{g}^{-1}$ $\mathrm{nl}^{-1}$ has a higher value $(86.2 \%)$ than serum albumin of $\leq 3.5 \mathrm{~g} /$ $\mathrm{nl}(75.9 \%)$, mGPS of $\geq 1(65.5 \%)$, and $\mathrm{mGPS}$ of $\geq 2(51.7 \%)$. This result implies that the use of a combination of serum albumin and age as the predictor of postoperative 30-day mortality in patients with colon cancer is better than that of serum albumin or mGPS alone.

On the basis of the AUCs derived for the prediction of 30day mortality in patients with colon cancer, we suggest that AAR is a better predictor than serum albumin in Taiwanese subjects. In conclusion, hypoalbuminemia often reflects malnourishment in patients [37]. In the meta-analysis of Braunschweig et al., malnourished patients benefited from parenteral nutrition in terms of mortality $[38,39]$. Such an approach has also been shown to reduce the postoperative complication rate by as much as $10 \%$ [40]. Hence, in order to reduce AAR as low as possible, our aim should be to initiate preoperative total parenteral nutrition for malnourished colon cancer patients.

\section{Acknowledgment}

This study was supported by a grant provided from the Chang Gung Memorial Hospital Research Program (CMRPF680021).

\section{Disclosure Statement}

The authors declare that there are no conflicts of interest.

\section{References}

1 Parkin DM: International variation. Oncogene 2004;23:6329-6340.

2 Parkin DM, Bray F, Ferlay J, Pisani P: Global cancer statistics, 2002. CA Cancer J Clin 2005;55: 74-108.

3 Stal A, Stembalska A, Šmigiel R, Tarkowski R, Grzebieniak Z, Sąsiadek M: Hereditary nonpolyposis colorectal cancer in Lower Silesia. Pol Przegl Chir 2007;79:182-189.
4 Winawer SJ: Colorectal cancer screening. Best Pract Res Clin Gastroenterol 2007;21:1031-1048.

5 Jemal A, Siegel R, Ward E, Hao Y, Xu J, Murray T, Thun MJ: Cancer statistics. CA Cancer J Clin 2008:58:71-96.

6 Center MM, Jemal A, Smith RA, Ward E: Worldwide variations in colorectal cancer. CA Cancer J Clin 2009:59:366-378.

7 www.doh.gov.tw/statistic/index.htm.
8 Longo WE, Virgo KS, Johnson FE, Oprian CA, Vernava AM, Wade TP, Phelan MA, Henderson WG, Daley J, Khuri SF: Risk factors for morbidity and mortality after colectomy for colon cancer. Dis Colon Rectum 2000;43:83-91.

9 Ansari MZ, Collopy BT, Hart WG, Carson NJ, Chandraraj EJ: In-hospital mortality and associated complications after bowel surgery in Victorian public hospitals. Aust N Z J Surg 2000;70:6-10. 
10 Sjo OH, Larsen S, Lunde OC, Nesbakken A: Short term outcome after emergency and elective surgery for colon cancer. Colorectal Dis 2008;11:733-739.

11 Frederiksen BL, Osler M, Harling H, Danish Colorectal Cancer Group, Ladelund S, Jørgensen $\mathrm{T}$ : The impact of socioeconomic factors on 30-day mortality following elective colorectal cancer surgery: a nationwide study. Eur J Cancer 2009;45: 1248-1256.

12 Lohsiriwat V, Chinswangwatanakul V, Lohsiriwat S, Akaraviputh T, Boonnuch W, Methasade A Lohsiriwat D: Hypoalbuminemia is a predictor of delayed postoperative bowel function and poor surgical outcomes in right-sided colon cancer patients. Asia Pac J Clin Nutr 2007;16:213-217.

13 Mullen JL, Buzby GP, Waldman MT, Gertner MH, Hobbs CL, Rosato EF: Prediction of operative morbidity and mortality by preoperative nutritional assessment. Surg Forum 1979;30:80-82.

14 Ondrula DP, Nelson RL, Prasad ML, Coyle BW, Abcarian H: Multifactorial index of preoperative risk factors in colon resections. Dis Colon Rectum 1992;35:117-122.

15 Bauer J, Capra S: Comparison of a malnutrition screening tool with subjective global assessment in hospitalised patients with cancer - sensitivity and specificity. Asia Pac J Clin Nutr 2003;12:257-260.

16 Sungurtekin $\mathrm{H}$, Sungurtekin U, Balci C, Zencir M, Erdem E: The influence of nutritional status on complications after major intraabdominal surgery. J Am Coll Nutr 2004;23:227-232.

17 Miner TJ, Brennan MF, Jaques DP: A prospective, symptom related, outcomes analysis of 1022 palliative procedures for advanced cancer. Ann Surg 2004;240:719-726.

18 Inoue Y, Miki C, Kusunoki M: Nutritional status and cytokine-related protein breakdown in elderly patients with gastrointestinal malignancies. J Surg Oncol 2004;86:91-98.

19 Gibbs J, Cull W, Henderson W, Daley J, Hur K, Khuri SF: Preoperative serum albumin level as a predictor of operative mortality and morbidity: results from the National VA Surgical Risk Study. Arch Surg 1999;134:36-42.

20 Damhuis RA, Tilanus HW: The influence of age on resection rates and postoperative mortality in 2773 patients with gastric cancer. Eur J Cancer 1995; 31A:928-931.
21 Yancik R, Wesley MN, Ries LAG, Havlik RJ, Long S, Edwards BK, Yates JW: Comorbidity and age as predictors of risk for early mortality of male and female colon carcinoma patients: a populationbased study. Cancer 1998;82:2123-2134.

22 Heriot AG, Tekkis PP, Smith JJ, Cohen CRG, Montgomery A, Audisio RA, Thompson MR, Stamatakis JD: Prediction of postoperative mortality in elderly patients with colorectal cancer. Dis Colon Rectum 2006;49:816-824.

23 Marusch F, Koch A, Schmidt U, Steinert R, Ueberrueck T, Bittner R, Berg E, Engemann R, Gellert K, Arbogast R, Körner T, Köckerling F, Gastinger I, Lippert H; Working Group Colon/Rectum Cancer: The impact of the risk factor 'age' on the early postoperative results of surgery for colorectal carcinoma and its significance for perioperative management. World J Surg 2005;29:1013-1021.

24 Alves A, Panis Y, Mathieu P, Mantion G, Kwiatkowski F, Slim K; Association Française de Chirurgie: Postoperative mortality and morbidity in French patients undergoing colorectal surgery: results of a prospective multicenter study. Arch Surg 2005;140:278-283.

25 Alves A, Panis Y, Mantion G, Slim K, Kwiatkowski F, Vicaut E: The AFC score: validation of a 4-item predicting score of postoperative mortality after colorectal resection for cancer or diverticulitis. Results of a prospective multicenter study in 1049 patients. Ann Surg 2007;246:91-96.

26 Gurevitch AJ, Davidovitch B, Kashtan H: Outcome of right colectomy for cancer in octogenarians. J Gastrointest Surg 2009:13:100-104.

27 Sun LC, Chu KS, Cheng SC, Lu CY, Kuo CH, Hsieh JS, Shih YL, Chang SJ, Wang JY: Preoperative serum carcinoembryonic antigen, albumin and age are supplementary to UICC staging systems in predicting survival for colorectal cancer patients undergoing surgical treatment. BMC Cancer 2009; 9:288

28 Klonoff-Cohen H, Barrett-Connor EL, Edelstein SL: Albumin levels as a predictor of mortality in the healthy elderly. J Clin Epidemiol 1992;45: 207-212.
29 Baumgartner RN, Koehler KM, Romero L, Garry PJ: Serum albumin is associated with skeletal muscle in elderly men and women. Am J Clin Nutr 1996;64:552-558.

30 Kestler HA: ROC with confidence - a Perl program for receiver operator characteristic curves. Comput Methods Programs Biomed 2001;64:133-136.

31 DeLong ER, DeLong DM, Clarke-Pearson DL Comparing the areas under two or more correlated receiver operating characteristic curves: a nonparametric approach. Biometrics 1988;44:837-845.

32 Chang $\mathrm{CH}$, Yen $\mathrm{CH}$, Chen MY: Using principal component analysis to develop a single-parameter screening tool for metabolic syndrome. BMC Public Health 2010;10:708-715.

33 Norman K, Lochs H, Pirlich M: Malnutrition as a prognostic factor. Chir Gastroenterol 2004;20: 175-180.

34 Agarwal N, Acevedo F, Leighton LS, Cayten CG, Pitchumoni CS: Predictive ability of various nutritional variables for mortality in elderly people. Am J Clin Nutr 1988;48:1173-1178.

35 Apelgren KN, Rombeau JL, Twomey PL, Miller RA: Comparison of nutritional indices and outcome in critically ill patients. Crit Care Med 1982; 10:305-307.

36 Fan ST, Lau WY, Yip WC, Poon GP, Yeung C, Lam WK, Wong KK: Prediction of postoperative pulmonary complications in oesophagogastric surgery. Br J Surg 1987;74:408-410.

37 Fuhrman MP, Charney P, Mueller CM: Hepatic proteins and nutrition assessment. J Am Diet Assoc 2004;104:1258-1264.

38 Braunschweig CL, Levy P, Sheean PM, Wang X Enteral compared with parenteral nutrition: a meta-analysis. Am J Clin Nutr 2001;74:534-542.

39 Hsu SD, Yu JC, Chen TW, Chou SJ, Hsieh HF, Chan DC: Role of nasogastric tube insertion after gastrectomy. Chir Gastroenterol 2007;23:303-306.

40 Torosian MH: Perioperative nutrition support for patients undergoing gastrointestinal surgery: critical analysis and recommendations. World J Surg 1999;23:565-569. 